\title{
Ecological impacts of time-variable exposure regimes to the fungicide azoxystrobin on freshwater communities in outdoor microcosms
}

\author{
Mazhar Iqbal Zafar · J. Dick M. Belgers • \\ Rene P. A. Van Wijngaarden - Arriënne Matser • \\ Paul J. Van den Brink
}

Accepted: 9 January 2012/Published online: 26 January 2012

(C) The Author(s) 2012. This article is published with open access at Springerlink.com

\begin{abstract}
This paper evaluates the effects of different time-varying exposure patterns of the strobilurin fungicide azoxystrobin on freshwater microsocosm communities. These exposure patterns included two treatments with a similar peak but different time-weighted average (TWA) concentrations, and two treatments with similar TWA but different peak concentrations. The experiment was carried out in outdoor microcosms under four different exposure regimes; (1) a continuous application treatment of $10 \mu \mathrm{g} / \mathrm{L}$ $\left(\mathrm{CAT}_{10}\right)$ for 42 days (2), a continuous application treatment of $33 \mu \mathrm{g} / \mathrm{L}\left(\mathrm{CAT}_{33}\right)$ for 42 days (3), a single application treatment of $33 \mu \mathrm{g} / \mathrm{L}\left(\mathrm{SAT}_{33}\right)$ and (4) a four application treatment of $16 \mu \mathrm{g} / \mathrm{L}\left(\mathrm{FAT}_{16}\right)$, with a time interval of 10 days. Mean measured 42-d TWA concentrations in the different treatments were $9.4 \mu \mathrm{g} / \mathrm{L}\left(\mathrm{CAT}_{10}\right)$, $32.8 \mu \mathrm{g} / \mathrm{L}\left(\mathrm{CAT}_{33}\right), 14.9 \mu \mathrm{g} / \mathrm{L}\left(\mathrm{SAT}_{33}\right)$ and $14.7 \mu \mathrm{g} / \mathrm{L}$ $\left(\mathrm{FAT}_{16}\right)$. Multivariate analyses demonstrated significant changes in zooplankton community structure in all but the $\mathrm{CAT}_{10}$ treated microcosms relative to that of controls. The largest adverse effects were reported for zooplankton taxa belonging to Copepoda and Cladocera. By the end of the experimental period (day 42 after treatment), community
\end{abstract}

M. I. Zafar · P. J. Van den Brink

Department of Aquatic Ecology and Water Quality

Management, Wageningen University, P.O. Box 47,

6700 AA Wageningen, The Netherlands

M. I. Zafar - J. D. M. Belgers - R. P. A. Van Wijngaarden ·

A. Matser · P. J. Van den Brink ( $\square)$

Alterra, Wageningen University and Research Centre,

P.O. Box 47, 6700 AA Wageningen, The Netherlands

e-mail: paul.vandenbrink@wur.nl effects were of similar magnitude for the pulsed treatment regimes, although the magnitude of the initial effect was larger in the $\mathrm{SAT}_{33}$ treatment. This indicates that for long-term effects the TWA is more important for most zooplankton species in the test system than the peak concentration. Azoxystrobin only slightly affected some species of the macroinvertebrate, phytoplankton and macrophyte assemblages. The overall no observed ecologically adverse effect concentrations (NOEAEC) in this study was $10 \mu \mathrm{g} / \mathrm{L}$.

Keywords Pesticides - Microcosm - Invertebrates · Time-variable exposure $\cdot$ Risk assessment $\cdot$ Azoxystrobin

\section{Introduction}

In the European Union (EU), ecological risk assessment of pesticides follows a tiered approach, which is laid down in the European pesticide regulation (European Commission 2009) and underlying guidance documents (European Commission 2002). For non-target aquatic organisms, higher-tier risk assessments traditionally have incorporated the results of additional laboratory and semi-field experiments evaluating a range of pesticide concentrations that have a single or repeated pulse exposure, or that are held constant for a short period of time. It has been recognised, however, that under field conditions, aquatic non-target organisms may be exposed to fluctuating concentrations of pesticide contaminants (Reinert et al. 2002) and consequently, in recent years, more attention has been paid to pulsed or intermittent exposure scenarios. Prediction of effects of pulsed or intermittent exposure on populations is becoming an important issue in ecotoxicology (Boesten et al. 2007; Van den Brink 2008). This issue was 
highlighted in a recent EU ELINK workshop (Brock et al. 2010), that resulted in recommendations for addressing time-variable exposures in aquatic risk assessment for pesticides, which developed guidance on when to use the peak or the time-weighted average (TWA) concentrations.

The present study evaluated the effects of azoxystrobin, a broad-spectrum, systemic fungicide belonging to the group $\beta$-methoxyacrylate strobilurins, with a biochemical mode of action that acts on respiration by inhibiting electron transport from cytochrome $B$ to cytochrome $C$. It was first marketed in 1996 and has since then been registered worldwide for use on a wide range of crops (Bartlett et al. 2002). A range of laboratory, field, or semi-field toxicity data have been published for the fungicide azoxystrobin (Maltby et al. 2009; Warming et al. 2009; Cole et al. 2000, see EFSA 2009 for a summary of this confidential report; Gustafsson et al. 2010).

Fungicides can be toxic to a wide array of aquatic nontarget organisms, and may affect the structure and function of biological communities (Maltby et al. 2009; Van den Brink et al. 2000; Slijkerman et al. 2004). According to our knowledge, no other information than that published in Cole et al. (2000) and Gustafsson et al. (2010) is available on the effects of strobilurin fungicides on aquatic systems of higher biological complexity than single species tests. Gustafsson et al. (2010) investigated the ecological effects of the fungicide azoxystrobin in outdoor brackish water microcosms and found that azoxystrobin is toxic to brackish water copepods at considerably lower concentration $(\leq 3 \mu \mathrm{g} / \mathrm{L})$ than previously reported for single species tests performed with freshwater crustaceans. Cole et al. (2000) tested the effects of a commercial formulation (YF9246, a $250 \mathrm{~g} / \mathrm{L}$ suspension concentrate) of azoxystrobin on freshwater microcosms and found that zooplankton were more sensitive than other endpoints, with transient effects reported at $10 \mu \mathrm{g} / \mathrm{L}$.

The present study was initiated to investigate, using azoxystrobin, which concentration profile, be it TWA or peak, is more appropriate for assessing the longer-term aquatic risks of this pesticide. This followed a similar microcosm study with the insecticide chlorpyrifos, which concluded that for most species, but not for all, the TWA concentration was more important than the peak concentration in explaining the longer-term effects (Zafar et al. 2011). The aim of the present study was to compare the effects of four different exposure regimes (two chronic, maintained exposure profiles, one repeated pulsed, and one single pulsed exposure regime) for the fungicide azoxystrobin. The high chronic and single pulse regimes had similar peak but different TWA concentrations, while the two pulsed regimes had different peak but similar TWA concentrations. The TWA concentrations of the two pulsed exposure regimes were intermediate relative to the two chronic regimes.

\section{Materials and methods}

\section{Experimental design}

Sixteen outdoor microcosms (diameter $1.8 \mathrm{~m}$, total depth $0.8 \mathrm{~m}$, water depth $0.5 \mathrm{~m}$, water volume ca. $1,270 \mathrm{~L}$ ) were used in the experiment. The microcosms were located at the Sinderhoeve Experimental Station (www.sinderhoeve. org) in Renkum near Wageningen, The Netherlands, and were lined with a watertight non-toxic layer of black polyethylene. Each microcosm was initially established with an $8 \mathrm{~cm}$ layer of sediment (fine clay) from a mesotrophic lake (dominated by the aquatic plants Elodea nuttallii and Chara sp.) and then filled with water, taken from the experimental station's water supply basin.

In the preparatory phase, one hundred shoots of Elodea nuttallii were planted on $75 \%$ of the sediment surface of each microcosm. In addition, other macrophytes (Eleocharis acicularis, Spirodela polyrhiza, Potamogeton berchtoldii, Potamogeton pectinatus, Elodea canadensis, Potamogeton crispus and Ranunculus circinatus) developed from diaspores in the sediment during the course of study. During the pre-treatment period (3 months approximately), phytoplankton, zooplankton and macroinvertebrates were collected from uncontaminated mesotrophic ditches situated at the Sinderhoeve Experimental Station, and Veenkampen, an experimental field site of Wageningen University, Wageningen, The Netherlands and introduced into the systems in order to develop a freshwater community characteristic for lentic, edge-of-field surface water. The macroinvertebrates introduced comprised several taxonomic groups and they were representatives of various trophic levels. Dominant species included crustaceans (Asellus aquaticus, Gammarus pulex and Daphnia sp.), insects (Cloeon dipterum, Chaoborus sp., Plea minutissima, Chironomidae, odonates and trichopterans), and the non-arthropods Hirudinea (Erpobdella sp.) and Gastropoda (Valvata sp.).

During the pre-treatment period all microcosms were interconnected by tubes and the water was circulated using a pump to achieve the development of a similar biocoenoses in the test systems. The circulation of water was stopped 3 weeks before the start of the experiment.

The microcosms were investigated over a period of 7 weeks. One week prior to the first applications, all biological endpoints were sampled once to establish pretreatment conditions, followed by a post treatment period of approximately 6 weeks.

Pesticide application and sampling

Azoxystrobin was provided by Syngenta Crop Protection AG, Switzerland as the formulated product AMISTAR ${ }^{\circledR}$ 
(Fluid) a $250 \mathrm{~g}$ a.i./L soluble concentrate formulation). There were four intended treatment regimes: (1) a continuous application treatment (CAT) of $10 \mu \mathrm{g} / \mathrm{L}\left(\mathrm{CAT}_{10}\right)$ consisting of a continuous exposure to $10 \mu \mathrm{g}$ a.i./ $\mathrm{L}$ for 42 days (2) a continuous application treatment of $33 \mu \mathrm{g} / \mathrm{L}$ $\left(\mathrm{CAT}_{33}\right)$ consisting of a continuous exposure to $33 \mu \mathrm{g}$ a.i./ $\mathrm{L}$ for 42 days (3) a single application treatment $\left(\mathrm{SAT}_{33}\right)$ consisting of a single application of $33 \mu \mathrm{g}$ a.i./L and (4) a four application treatment $\left(\mathrm{FAT}_{16}\right)$ consisting of four applications, each achieving a peak of $16 \mu \mathrm{g}$ a.i./L with a time interval of 10 days. The treatment levels of the $\mathrm{SAT}_{33}$ and $\mathrm{FAT}_{16}$ applications were based on the 42d-TWA of $15 \mu \mathrm{g}$ a.i./L, which fell in between the chronic exposure regimes of $\mathrm{CAT}_{10}$ and $\mathrm{CAT}_{33}$. The concentrations in the chronic tests were kept constant between 80 and $120 \%$ of desired nominal concentrations by adding more azoxystrobin during exposure. To measure the exposure concentrations, water samples from all microcosm were collected regularly (see Fig. 1). In the continuous exposure treatments, sampling and analysis of azoxystrobin were performed every 1-2 days, with dosing as necessary to maintain the concentration. Approximately $1 \mathrm{~h}$ after the additional application, a water sample was taken and the concentration analysed as described below. Before application, concentrations in stock and dosing solutions were checked for establishing nominal initial concentrations. The first treatment day is referred to as day 0 , the first sampling as day -7 while the post first treatment days run up to day 43.

The microcosms were randomly allocated to the different treatments. All treatments were performed in triplicate with four control replicates. Azoxystrobin was applied by pouring a defined volume of dosing solution into the microcosms. The control microcosms were treated with water only. The systems were gently stirred immediately after application to promote the mixing through the water column whilst avoiding any resuspension of sediment particles and disturbance of submerged macrophytes.

Calculation of treatment level for time-variable exposures

Azoxystrobin was selected as a compound for this study, as it has a measured waterphase $\mathrm{DT}_{50}$ of 13 days in an outdoor aquatic microcosm (Jones and Lake 2000, see EFSA 2009 for a summary of this confidential report). In addition, with a $\log \mathrm{K}_{\mathrm{ow}}$ of 2.5 azoxystrobin would be expected to remain mainly in the water phase (Tomlin 2011). Due to its relatively slow dissipation, exposures would be expected to be moderate to long-term. The concentrations of azoxystrobin chosen were based on the $10 \mu \mathrm{g} / \mathrm{L}$ NOEAEC (no observed ecologically adverse effect concentration (effect class 2/slight effects)) derived from a single application to an outdoor pond microcosm study (Cole et al. 2000).
Fig. 1 Dynamics of azoxystrobin concentrations in microcosms water during the 42 days period a continuous exposure of $10 \mu \mathrm{g} / \mathrm{L}$, b continuous exposure of $33 \mu \mathrm{g} / \mathrm{L}$, c single application and $\mathbf{d}$ four application treatments. The four applications took place on day $0,10,20$ and 30
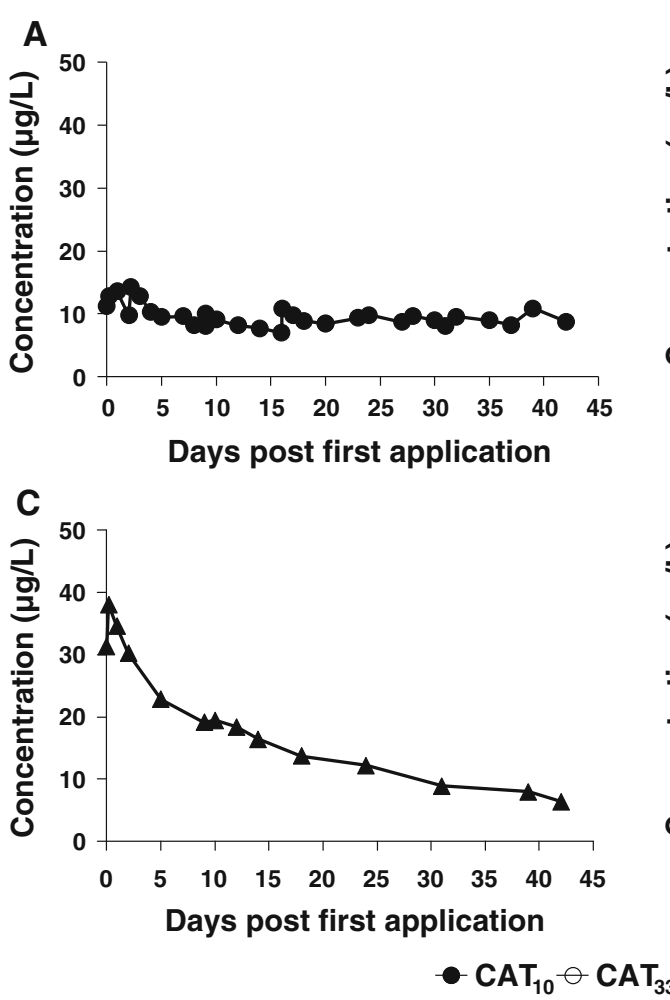

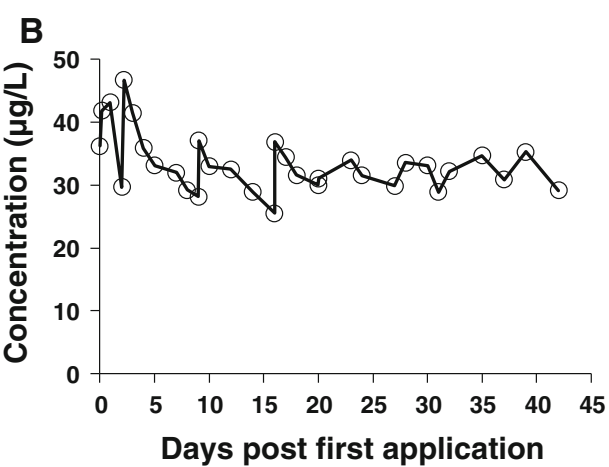

D

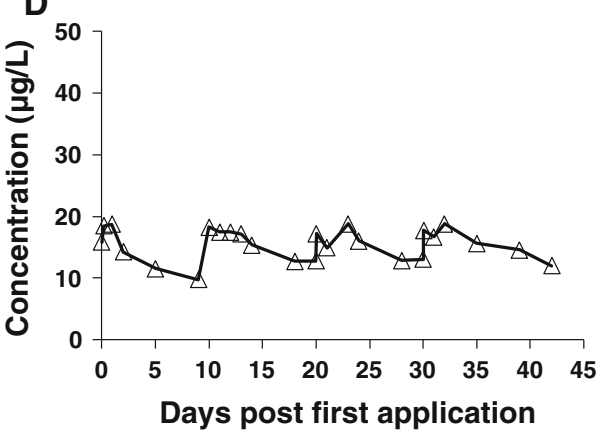


More pronounced effects may be expected when this concentration is maintained. Therefore, the intention was for the concentration in $\mathrm{CAT}_{10}$ to be equal to the 42d-TWA in $\mathrm{SAT}_{33}$ and $\mathrm{FAT}_{16}$ (calculations according to Zafar et al. (2011)). However, azoxystrobin proved to be more persistent in our microcosms and consequently the TWA concentration of the $\mathrm{SAT}_{33}$ and $\mathrm{FAT}_{16}$ were $15 \mu \mathrm{g} / \mathrm{L}$ instead of $10 \mu \mathrm{g} / \mathrm{L}$, and therefore this TWA concentration fell in between $\mathrm{CAT}_{10}$ and $\mathrm{CAT}_{33}$.

\section{Azoxystrobin analysis}

The concentrations of azoxystrobin were determined in the water samples by taking depth-integrated water samples from the microcosms by means of stainless steel suction tubes connected to glass flasks (Schott bottle, $250 \mathrm{~mL}$ ) using a vacuum pump. Approximately $100 \mathrm{~mL}$ of water were sampled from each microcosm in duplicate. Duplicate $2 \mathrm{~mL}$ samples from the $100 \mathrm{~mL}$-water sample were transferred into 4-mL WISP vials (borosilicate) containing $2 \mathrm{~mL}$ of acetonitrile. The exact mass of water added was calculated by weighing the vials. The vials were closed with a cap and thoroughly shaken manually. A $2 \mathrm{~mL}$ high performance liquid chromatograpy (HPLC) vial was then filled with a portion of the sample, and was then sealed and analysed by Liquid chromatography-mass spectrometry with Triple Quadrupole systems (P2600 Agilent 6410 LCMS/MS QQQ). The volume injected was $50 \mu \mathrm{L}$ with an autosampler and the mobile phase (HPLC - water/acetonitrile; $(50 / 50, \mathrm{~V} / \mathrm{V})$ was set at a flow rate of $1.0 \mathrm{~mL} / \mathrm{min}$. The analytical column used was an Agilent Zorbax Eclipse XDB-C18 (Diameter $4.6 \mathrm{~mm}$; Length $150 \mathrm{~mm} ; 5 \mu \mathrm{m}$ ). Column was set at temperature $40^{\circ} \mathrm{C}$. Under these conditions, the retention time of azoxystrobin was approximately $2.40 \mathrm{~min}$.

TWA concentrations of azoxystrobin were based on area under the curve (AUC) calculations, and the $\mathrm{DT}_{50}$ in $\mathrm{SAT}_{33}$ was estimated assuming first-order dissipation kinetics. Dissipation times were based on measurements for water samples above the limit of quantification (LOQ). The Level of Detection (LOD) and LOQ of the analysis were determined by adding a standard $0.01 \mu \mathrm{g} / \mathrm{L}$ of azoxystrobin in acetonitrile/water (v/v: 50/50) to each injection series. The concentration of this standard of $0.01 \mu \mathrm{g} / \mathrm{L}$ azoxystrobin was calculated from the calibration curve, while the standard itself was not part of this calibration curve. In total, this standard was injected 105 times, yielding an average concentration of $0.0208 \mu \mathrm{g} / \mathrm{L}$, with a standard deviation (SD) of $0.0048 \mu \mathrm{g} / \mathrm{L}$. The LOD in water sample was defined as $3 \times \mathrm{SD}(3 \times 0.0048=0.015 \mu \mathrm{g} / \mathrm{L})$, the $\mathrm{LOQ}$ as $10 \times \mathrm{SD}(10 \times 0.0048=0.05 \mu \mathrm{g} / \mathrm{L})$. The $\mathrm{DT}_{50}$ was calculated by means of linear regression using ln-transformed measured pesticide concentrations versus time.
Macroinvertebrates

Artificial substrates, consisting of litter bags (see "Decomposition" section) and pebble baskets, were used to monitor the effects of azoxystrobin on the benthic macroinvertebrate assemblage. Two pebble baskets and two litter bags were placed on concrete tiles on the sediment in each microcosm 2 weeks before the initiation of the treatments in order to allow colonisation by macroinvertebrates (for a detailed description of methods see Brock et al. (1992)).

Macroinvertebrates were sampled five times from each microcosm at days $-7,3,10,17$ and 43 . Pebble baskets were gently retrieved using a net. The litter bags were collected by hand. The substrates were first washed in a container to remove invertebrates. The macroinvertebrates were identified and counted alive, and then released back into the their original microcosms. The animals were identified to the lowest practical taxonomic level. From each microcosm abundance of macroinvertebrates from pebble baskets and litter bags were pooled prior to analysis of the data.

Phyto- and zooplankton sampling and identification

Zooplankton and phytoplankton were simultaneously sampled on days $-5,2,9,16,23,32$ and 44 days by using a Perspex (Poly(methyl methacrylate)) tube (volume = $1.8 \mathrm{~L}$ ). Depth-integrated water samples were collected from several spots in each microcosm until a bulk water sample of $12 \mathrm{~L}$ had been obtained in a bucket. From this bulk sample, $5 \mathrm{~L}$ was passed through a $55 \mu \mathrm{m}$ mesh net to collect zooplankton. Another $5 \mathrm{~L}$ was passed through a $20 \mu \mathrm{m}$ mesh net to collect phytoplankton, possibly missing the smaller phytoplankton taxa. The concentrated plankton samples were preserved with acetate buffered Lugol's solution in a $100 \mathrm{~mL}$ sampling vial. The filtered water was returned into its original microcosm.

Cladocerans, copepods and ostracods (macro-zooplankton) were counted using a stereo microscope (Nikon SMZ-10, magnification $25 \times$ ). Rotifers and copepod nauplii (micro-zooplankton) were quantified and identified with an inverted microscope (Carl Zeiss, Axiovert 10, magnification $100 \times$ ), using a sub-sample of known volume. Rotifers and cladocerans were identified to the lowest practical taxonomic level (i.e., genus or species level), whereas copepods were identified to the suborder by classifying as calanoids or cyclopoids. A distinction was also made between nauplii and the more mature stages of the copepods.

Phytoplankton species composition was studied by counting the number of cells of a known volume which were identified to the lowest practical taxonomic level. 
Taxa and number of cells were based on a maximum of 200 observations, consisting of a series of 20-40 counting fields of a single cuvette under an inverted microscope (magnification $400 \times$ ). Zooplankton and phytoplankton data were expressed as number of individuals per litre.

\section{Chlorophyll- $a$}

Phytoplankton chlorophyll- $a$ was sampled in parallel with the phyto- and zooplankton sampling. One litre of the remaining from the bulk 12-1 sample was used to determine the amount of chlorophyll- $a$ of the phytoplankton. Samples were concentrated through a $1.2 \mu \mathrm{m}$ pore size Whatmann glass-fibre filter (GF/C; diameter $4.7 \mathrm{~cm}$; Maidstone, UK) using a vacuum pump. The filters containing phytoplankton were transferred into Petri dishes, wrapped in aluminium foil, and stored in a freezer at a temperature of $-70^{\circ} \mathrm{C}$ until analysis. After ethanol extraction of the pigments, measurements of chlorophyll- $a$ content were performed using a HPLC with fluorescence detection (Webb et al. 1992).

As an estimate of periphytic algal biomass, chlorophyll$a$ was sampled on day -5 and on days $2,9,16,23,32$ and 42. Periphyton was sampled from glass microscope slides $(7.6 \times 2.6 \mathrm{~cm})$ that served as artificial substrates. The slides were positioned vertically in a stainless steel frame placed in the centre of all microcosm in the north-south position tied on a long rod, approximately $10 \mathrm{~cm}$ below the water surface of each microcosm, and incubated for 2 weeks. The placement of frame was kept the same in all test systems during whole experimental period. On each sampling day, 8 glass slides per microcosm (colonised for 14 days) were scraped visually clean with blades (Applo Ever-Sharp-Blades; Solingen-Germany) collecting the removed periphyton in tap water. New clean slides were then reintroduced in the microcosm. The chlorophyll$a$ content of the water periphyton solution was analysed as described above for the phytoplankton.

\section{Water quality parameters}

Dissolved oxygen (DO), pH, electrical conductivity (EC) and temperature $(\mathrm{T})$ were measured in each microcosms on days $-5,2,9,16,23,32$ and 42 to detect possible changes in community metabolism. On sampling days, measurements were carried out in the morning just around the start of photoperiod, at approximately $25 \mathrm{~cm}$ below the water surface. $\mathrm{h}$ DO, $\mathrm{pH}$ and $\mathrm{T}$ were measured using a HQ40D multimeter (Hach-Lange, The Netherlands) and EC was measured with an Eijkelkamp 18.28 conductivity meter.

Alkalinity levels were determined in all microcosms prior to the initiation of the treatments (day -5$)$ and at the end (day 43) of the experiment, using $100-\mathrm{mL}$ water samples taken at a depth of $10 \mathrm{~cm}$ by titrating with $0.02 \mathrm{~N}$ $\mathrm{HCl}$ until a pH of 4.2 was reached (pH meter: WTW 323).

Additionally, the concentration of ammonia, nitrate, nitrite, total nitrogen, orthophosphate and total phosphate were measured in the control microcosms at the start of the experiment and in all microcosms at end of experiment (day 42). For this purpose, water samples (approximately $100 \mathrm{~mL}$ ) were obtained from the filtered water (Whattman GF/C; $1.2 \mu \mathrm{m}$ pore-size) collected for phytoplankton chlorophyll- $a$ samples. These samples were transferred into $100-\mathrm{mL}$ polyethylene flasks which were stored at below $-18^{\circ} \mathrm{C}$ until analysis. Total soluble nitrogen, $\mathrm{N}-\left(\mathrm{NO}_{2}{ }^{-}+\mathrm{NO}_{3}{ }^{-}\right), \mathrm{NH}_{4}{ }^{+}$, ortho-phosphate and total phosphate were analysed using a Skalar 5100 Autoanalyser.

\section{Decomposition}

Decomposition of particulate organic matter (POM) was determined using litter bags (Brock et al. 1982), containing Populus $\times$ canadensis (hybrid black poplar) leaves. In the decomposition assessment, a portion of $2 \mathrm{~g}$ dry weight (dried at $60^{\circ} \mathrm{C}$ ) of leaves were enclosed in each litter bag. The litter bags were made from a glass Petri-dish (diameter: $11.6 \mathrm{~cm})$, closed with a cover of stainless-steel wire (mesh size: $0.7 \times 0.7 \mathrm{~mm}$ ), in which two holes (diameter: $0.5 \mathrm{~cm}$ ) were punched to give invertebrates access to the leaves.

In each microcosm, two litter bags were placed at the sediment surface in an almost upright position for a 2-week incubation period. At the end of the incubation period, litter bags were emptied into a white tray to separate POM from adhering sediment particles and macroinvertebrates by rinsing with tap water. After sampling, a new set of litterbags was incubated. Remaining organic plant material was dried in pre-weighted aluminium foil at $105^{\circ} \mathrm{C}$ for $48 \mathrm{~h}$ to obtain dry weight. The decomposition over a 2-week period was expressed as \% remaining organic material.

Macrophyte cover, biomass and bioassay

Development of macrophyte species composition and macrophyte species cover was examined three times on days $-1,14$, and 44 days. Development of vegetation and the species-composition of macrophytes were investigated by monitoring macrophyte cover and abundance. The monitoring only involved the $75 \%$ of the sediment surface that was initially planted. Cover values were estimated using ordinal scales of $1(<1 \%), 2(1-5 \%), 3(5-12.5 \%), 4$ (12.5-25\%), 5 (25-50\%), 6 (50-75\%), 7 (75-100\%).

At the last sampling date (day 42), aboveground biomass of all macrophyte species were harvested for each microcosm. The plant material harvested was rinsed under tap water to remove sediment particles and macroinvertebrates 
and then dried in an oven in pre-weighed aluminium foil at $105^{\circ} \mathrm{C}$ for $48 \mathrm{~h}$ to determine the dry weight.

In addition to total macrophyte analysis, a Myriophyllum spicatum bioassay was performed. Flower pots (height $9.5 \mathrm{~cm}: 9 \mathrm{~cm}$ diameter) were filled with approximately $8.5 \mathrm{~cm}$ depth of sediment consisting of $86 \%$ peat, $8 \%$ sand, $6 \%$ clay and $3.73 \mathrm{~kg}$ fertiliser $/ \mathrm{m}^{3}$ (slow release). Each pot received three apical shoots of $M$. spicatum with a length of $10 \mathrm{~cm}$ and with at least one node in the sediment. Only unbranched, non-flowering apical Myriophyllum shoots without roots were selected. In the pre-treatment period at day $-21,500$ pots were introduced into one of the ditches at the Sinderhoeve Experimental Station. At day -4, 12 pots per microcosm with healthy plants were placed in plastic trays on the macrophyte-free sediment section. On day $-3,16 \mathrm{M}$. spicatum pots (one from each test cosm) were sampled to characterise the plant material (i.e., shoot and root dry weight $\left(105^{\circ} \mathrm{C}\right.$ for $\left.24 \mathrm{~h}\right)$, shoot length and shoot number) at the time of the first application. On days 14 and 42, 6 pots per microcosm were harvested. The plants were rinsed thoroughly to remove sediment particles. The endpoints (mean per shoot) measured were aboveground dry weight, belowground dry weight (roots), total length of shoots (length of main shoot and length of side shoots), mean length of shoots (total length of shoots/ total \# of side shoots), and number of side shoots. For each bioassay, belowground material (roots) was separated from the aboveground parts and plant samples were dried in aluminium foil $\left(105^{\circ} \mathrm{C}, 48 \mathrm{~h}\right)$ and weighed.

Data analysis

\section{Univariate analysis}

Prior to univariate and multivariate analyses, abundance data of macroinvertebrates, phytoplankton and zooplankton were $\ln (\mathrm{ax}+1)$ transformed, where $\mathrm{x}$ stands for the abundance value and ax makes 2 by taking the lowest abundance value higher than zero. We deviated from the usual $\ln (x+1)$ transformation because the data set frequently showed low or high abundance values (i.e., 1 individual per substratum for macroinvertebrates, 0.2 individuals per litre for the zooplankton and 2 individuals per litre for the phytoplankton community). We decided that the factor ax in the $\ln (a x+1)$ transformation should make 2 by taking the lowest abundance value higher than zero for $\mathrm{x}$. A factor of two was chosen to avoid false discrepancy between zero abundance values and low abundance values. Since, for instance, the lowest abundance value higher than zero in the zooplankton data sets was 0.2, a factor 10 was used (Van den Brink et al. 2000). All other variables were tested using untransformed values. Statistically significant differences between the treatments as well as against controls were assessed for all parameters or taxon levels at each time point, using analysis of variance (ANOVA) with multiple comparison tests. ANOVA was followed by Duncan's multiple-range test $(p<0.05)$, testing all treatments against the controls but also against each other. The analyses were carried out with the Genstat computer programme (v11.1, Laws Agricultural Trust, 2009 by VSN International Ltd). If the endpoint was measured more than three times after the initiation of the treatments, effects were only considered when they were consistent, i.e., occurring on least two consecutive sampling dates.

\section{Multivariate analysis}

The effects of azoxystrobin treatment at the community level of macroinvertebrates, zooplankton and phytoplankton were analysed by the Principal Response Curves (PRC) method using the CANOCO software package, version 4.5 (Ter Braak and Smilauer 2002; Van den Brink and ter Braak 1999). The analysis results in a diagram showing sampling day on the $x$-axis and the first Principal Component of the treatment effects on the community on the $y$-axis (e.g., Fig. 2). The PRC method yields a diagram showing the most dominant community response to the treatment present in the data set. The species weights are shown in a separate diagram, and indicate the degree of affinity the species have with this dominant response. The results of the PRC analysis can also be evaluated in terms of the fractions of variance explained by the factors time and treatment, and the PRC diagram shows the fraction of the variance that is explained by the treatment.

In the CANOCO computer programme, redundancy analysis is accompanied by Monte Carlo permutation tests to assess the statistical significance of the effects of the treatments on the species composition of the microcosms. The significance of the PRC diagram, in terms of displayed treatment variance, was tested by Monte Carlo permutation of microcosms, using an $F$-type test statistic based on the eigenvalue of the component (van den Brink and ter Braak 1999). For each sampling date, all treatments were also tested against the controls using Monte Carlo permutation tests to assess the significance of treatment effects in time.

\section{Results}

Exposure to azoxystrobin

Dosing solutions corresponded well (108 $\pm 8 \%$; mean \pm SD) with the nominal concentrations, although measured peak concentrations of azoxystrobin exposure $4 \mathrm{~h}$ after the applications were higher than nominal (Table 1). Table 1 shows that the TWA exposure 
Fig. 2 Principal response curves resulting from the analysis of the zooplankton dataset, indicating the effects of different azoxystrobin treatments. Nineteen percent of all variance could be attributed to the sampling date; this is displayed on the horizontal axis. Twenty-six percent of all variance could be attributed to treatment level, $35 \%$ of which is displayed on the vertical axis. The lines represent the development of the treatments in time. The species weight $\left(b_{k}\right)$ can be interpreted as the affinity of a taxon with the Principal Response Curves $\left(\mathrm{c}_{\mathrm{dt}}\right)$. Taxa with a species weight between 0.25 and -0.25 are not shown. A Monte Carlo permutation test indicated that the diagram displays a significant amount of the variance explained by the treatment $(p=0.004)$

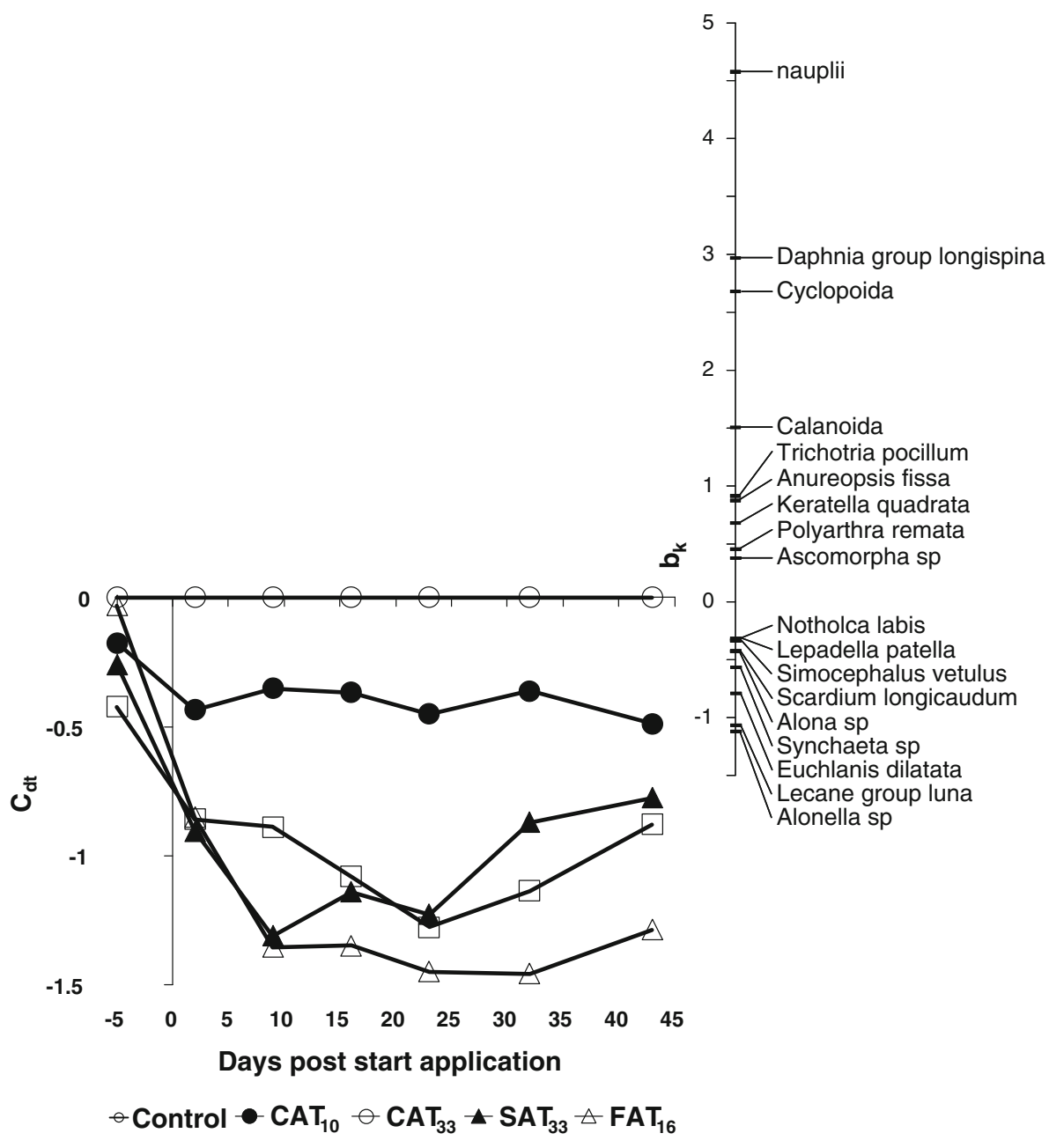

Table 1 Nominal, peak and time-weighted average (TWA) concentrations ( $\mu \mathrm{g} / \mathrm{L})$ of azoxystrobin during the treatment periods (days $0-42$ )

\begin{tabular}{llllllll}
\hline $\begin{array}{l}\text { Treatment } \\
\text { exposure } \\
\text { regimes }\end{array}$ & $\begin{array}{l}\text { Intended } \\
\text { conc. } \\
(\mu \mathrm{g} / \mathrm{L})\end{array}$ & $\begin{array}{l}\text { Nominal } \\
\text { initial } \\
\text { conc. }(\mu \mathrm{g} / \mathrm{L})\end{array}$ & $\begin{array}{l}\text { \% of nominal } \\
\text { initial } \\
\text { conc. }(\%)\end{array}$ & $\begin{array}{l}\text { Measured peak } \\
\text { conc. }(4-\mathrm{h} \text { after } \\
\text { application) }(\mu \mathrm{g} / \mathrm{L})\end{array}$ & $\begin{array}{l}\text { \% of measured } \\
\text { peak conc. }(\%)\end{array}$ & $\begin{array}{l}\text { TWA } \\
(0-42 \text { days }) \\
(\mu \mathrm{g} / \mathrm{L})\end{array}$ & $\begin{array}{l}\% \text { of TWA } \\
\text { conc. }(\%)\end{array}$ \\
\hline $\mathrm{CAT}_{10}$ & 10 & 11.7 & 117 & 12.9 & 129 & 127 & 9.35 \\
$\mathrm{CAT}_{33}$ & 33 & 37.1 & 112 & 41.9 & 121 & 32.8 & 93.5 \\
$\mathrm{SAT}_{33}$ & 33 & 32.8 & 104 & 38.1 & 121 & 14.9 \\
$\mathrm{FAT}_{16}$ & 15.8 & 15.7 & 99.3 & 18.4 & 14.7 & 99.3 \\
\hline
\end{tabular}

Nominal initial concentrations are based on the concentrations measured in treatment solutions

All concentrations are presented as means of three replicates

concentrations in $\mathrm{CAT}_{10}$ and $\mathrm{CAT}_{33}$ were as planned and TWA concentrations in the $\mathrm{SAT}_{33}$ and $\mathrm{FAT}_{16}$, at 14.9 and $14.7 \mu \mathrm{g} / \mathrm{L}$, respectively, were almost identical over the period 0-42 days.

The dynamics in measured concentrations of azoxystrobin in microcosms treated with different application regimes are illustrated in Fig. 1. In the continuous exposure treatment regimes, the highest measured concentration in
$\mathrm{CAT}_{10}$ was $14.3 \mu \mathrm{g} / \mathrm{L}$ on day 2.2 and the lowest was $7.0 \mu \mathrm{g} / \mathrm{L}$ on day 16 (Fig. 1a), while the exposure concentration in $\mathrm{CAT}_{33}$ was rather higher than target concentration directly after application and fluctuated in the beginning, becoming less variable from day 7 to 42 (Fig. 1b). The highest measured concentrations in $\mathrm{CAT}_{33}$ were $41.9,43.1$, and $46.7 \mu \mathrm{g} / \mathrm{L}$ on days $0.17,1.0$ and 2.2 , respectively and the lowest was $25.6 \mu \mathrm{g} / \mathrm{L}$ on day 16 . At 
the end of experiment (day 42), the measured azoxystrobin concentration in the $\mathrm{SAT}_{33}$ was approximately $20 \%$ of the nominal applied (Fig. 1c).The $\mathrm{DT}_{50}$ from water-phase as calculated from the concentration dynamics in the $\mathrm{SAT}_{33}$ was 18 days. The $\mathrm{FAT}_{16}$ shows four pulses followed by slow dissipation between applications (Fig. 1d). After 9 days, exactly one day before the 2nd application in the FAT $_{16}$ treatment, $53 \%$ of the initial measured test concentration was still present, while on day 20 and 30, just before the 3rd and 4th application 69 and $71 \%$ of subsequent applications were detected, respectively.

\section{Zooplankton}

Over the experimental period, a total of 46 different zooplankton taxa were identified in the microcosms. In terms of total abundance, the zooplankton community was dominated by Rotifera and Copepoda followed by Cladocera and Ostracoda. Rotifera were the most diverse taxonomic group with 33 taxa and $80 \%$ of total zooplankton abundance. Four taxa belonged to the Trichocerca family making it the most diverse genus, followed by Lecane sp. (two species) and Keratella sp. (two species). Among the rotifers, Polyarthra remata was the dominant species $(37 \%$ of the total zooplankton abundance), followed by Synchaeta sp. (10\%), Keratella quadrata (9\%) and Hexarthra sp. (9\%). Cladocera were represented by 9 taxa, Copepoda by 3 taxa (copepod nauplii, Cyclopoida, Calanoida) and Ostracoda by 1 taxon (not further identified). Copepod nauplii accounted for $15 \%$ of total zooplankton abundance and had a high abundance throughout the experimental period in the controls, with an average of 200 individuals/L.

The Monte Carlo permutation tests indicated that significant treatment-related effects were observed in $\mathrm{CAT}_{33}$, $\mathrm{SAT}_{33}$ and $\mathrm{FAT}_{16}$ (Table 2). The effects of azoxystrobin application on zooplankton community structure are visualised in the PRC diagram presented in Fig. 2. The PRC diagram of the zooplankton data set revealed small non- significant variation in the pre-treatment period but substantial treatment-dependent differences to the controls after the start of the treatments. The zooplankton community response was characterised by pronounced effects in all azoxystrobin treatments except $\mathrm{CAT}_{10}$. Up until day 9, the treatment-related responses of the zooplankton community in the $\mathrm{SAT}_{33}$ and $\mathrm{CAT}_{33}$ treatments, characterised by more or less the same initial peak concentration, were similar, but after that the $\mathrm{SAT}_{33}$ treatment showed a trend of recovery in contrast to the $\mathrm{CAT}_{33}$ treatment (Fig. 2). Initially (day 9), the treatment-related response of the zooplankton community was more pronounced in the $\mathrm{SAT}_{33}$ than in the $\mathrm{FAT}_{16}$ treatment, but later on, responses between these treatments (characterised by the same $42-\mathrm{d}$ TWA concentration) were very similar (Fig. 2). The deviation of treatments from the controls was consistent with the results of Monte Carlo tests (Table 2). The high positive species-weight $\left(b_{k}>1.5\right)$ of all Copepoda (copepod nauplii, Cyclopodia, Calanoida) and one Cladocera species (Daphnia gr. longspina) in the PRC diagram (Fig. 2) indicate that abundances of these taxa correlated best with the community response, herewith showing a treatment-related decline. Several taxa belonging to Rotifera, such as Lecane gr. luna, Euchlanis dilatata, Synchaeta sp. and Scaridium longicaudum, and the cladocerans Alonella sp. and Alona sp. had a weak negative species-weight score $\left(b_{K}<-1\right.$; Fig. 2$)$, suggesting a small treatment-related increase.

The dynamics of the four taxa that showed consistent statistically significant (Duncan test; $p<0.05$ ) treatment related differences in the univariate analyses are shown in Fig. 3. These responses at the taxon level are in accordance with their high species-weight in the PRC diagram. Treatment-related effects on nauplii became apparent soon after application, particularly for the $\mathrm{CAT}_{33}$ and $\mathrm{SAT}_{33}$ treatments, followed by $\mathrm{FAT}_{16}$ and $\mathrm{CAT}_{10}$. The most pronounced effects in terms of magnitude and duration were observed for $\mathrm{CAT}_{33}$ which was significantly different

Table 2 Results of Monte Carlo permutation tests performed on the zooplankton data set

\begin{tabular}{lllllllllll}
\hline Day & Control & Control & Control & Control & CAT $_{10}$ & CAT $_{10}$ & CAT $_{10}$ & CAT $_{33}$ & CAT $_{33}$ & SAT $_{33}$ \\
& versus & versus & versus & versus & versus & versus & versus & versus & versus \\
& CAT $_{10}$ & CAT $_{33}$ & SAT $_{33}$ & FAT $_{16}$ & CAT $_{33}$ & SAT $_{33}$ & FAT $_{16}$ & SAT $_{33}$ & FAT $_{16}$ & FAT $_{16}$ \\
\hline
\end{tabular}

\begin{tabular}{lccccc}
\hline-5 & & & & & \\
2 & 0.03 & $(0.10)$ & 0.03 & & \\
9 & 0.03 & 0.03 & 0.03 & $(0.09)$ & $(0.09)$ \\
16 & 0.03 & & $(0.07)$ & & \\
23 & 0.03 & 0.03 & 0.03 & $(0.09)$ & \\
32 & 0.03 & & & $(0.09)$ \\
43 & 0.03 & & 0.03 & &
\end{tabular}

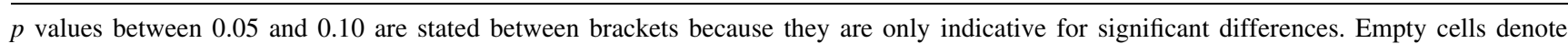
$p$ values larger than 0.100 
Fig. 3 Zooplankton population dynamics, in numbers per litre (geometric mean), of taxa showing consistent responses to azoxystrobin treatments. Nauplii (a), Calanoida (b), Cyclopoida (c) and Daphnia gr. longispina (d). Significant differences are indicated by the circles. Treatments present in the same circle did not differ significantly from each other, while those not sharing the same circle did differ significantly (Duncan test, $p<0.05$ ). The value 0.01 denotes 0 numbers in the samples
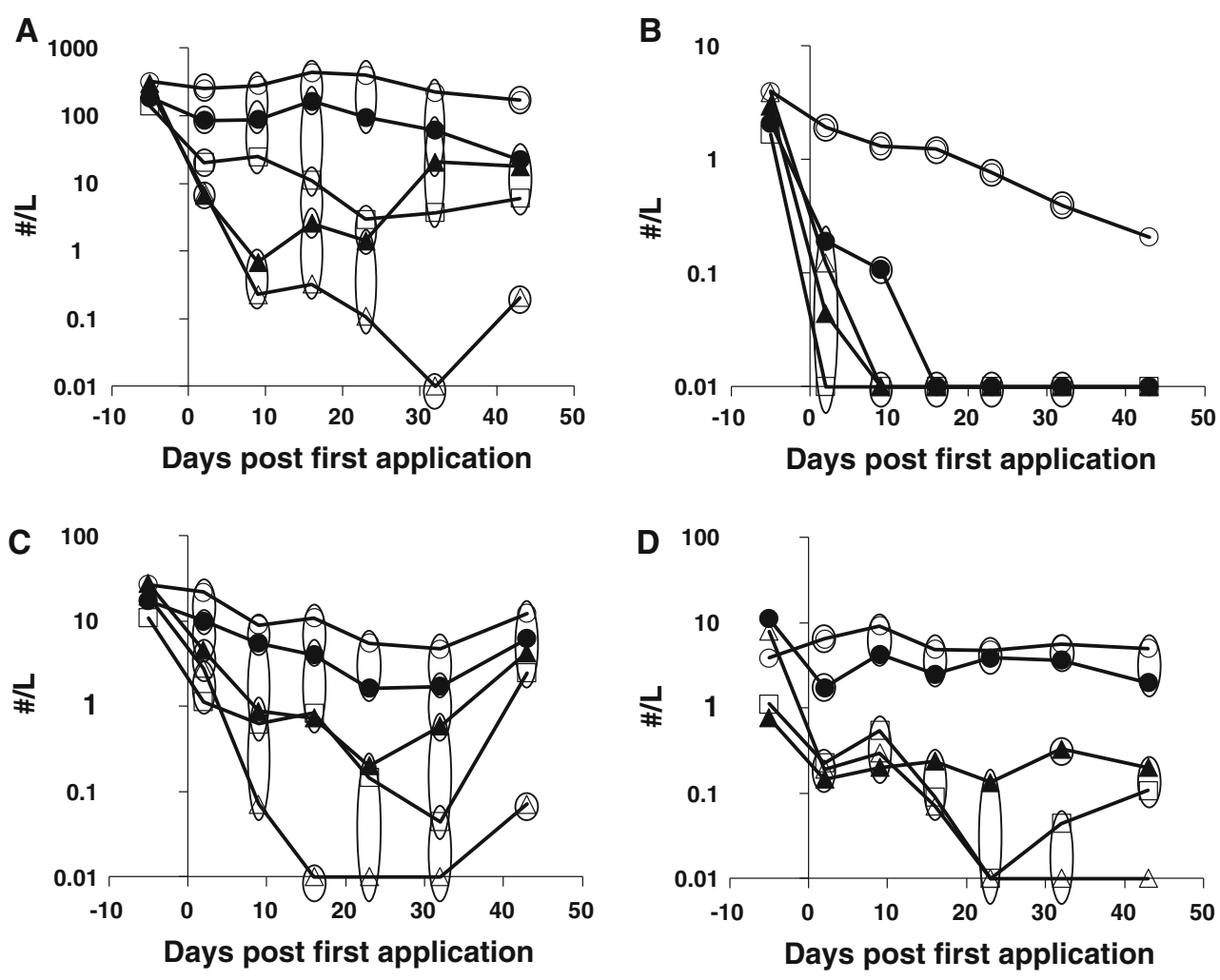

$\bullet$ Control $\bullet \mathrm{CAT}_{10} \odot \mathrm{CAT}_{33} \star \mathrm{SAT}_{33} \triangle \mathrm{FAT}_{16}$ from other treatments on day 32 and 43 (Fig. 3a). In the course of the experiment, mean densities of nauplii were somewhat lower in the $\mathrm{CAT}_{10}$ treatment when compared to controls but for $\mathrm{CAT}_{10}$, statistically significant effects were only apparent on two isolated sampling days (day 2 and 43) (Fig. 3a). Again the responses of nauplii in $\mathrm{SAT}_{33}$ and $\mathrm{CAT}_{33}$ treatment (similar initial peak concentration) were similar up until day 9. At the end of the experiment, densities of nauplii were very similar in the $\mathrm{SAT}_{33}$ and $\mathrm{FAT}_{16}$ treatments (characterised by similar 42-d TWA concentration). Calanoida disappeared from the $\mathrm{FAT}_{16}$ microcosms 2 days after the first application, followed by $\mathrm{SAT}_{33}$, $\mathrm{CAT}_{33}$ and $\mathrm{CAT}_{10}$, respectively (Fig. 3b). Statistically significant differences relative to the controls remained apparent in all treatments throughout the experiment, except for the last sampling date (day 43), which was a result of a decrease of abundance of calanoids in the controls (Fig. 3b). Note that densities of Calanoida already were low in all test systems prior to fungicide application. Cyclopoida showed prominent effects in all treatments except for the treatment $\mathrm{CAT}_{10}$ (Fig. 3c). $\mathrm{CAT}_{33}$ was significantly different from all other treatments on days 17 and 43 and showed a decline in abundance until the last sampling date. Statistical analysis indicated that partial recovery had occurred in the $\mathrm{SAT}_{33}$ and $\mathrm{FAT}_{16}$ treatments by the end of the study. No consistent significant effects were detected for $\mathrm{CAT}_{10}$ (Fig. 3c). Azoxystrobin had adverse effects on the abundance of the $D$. gr. longispina populations in all treatments in the first week after application (Fig. 3d). D. gr. longispina completely disappeared in $\mathrm{CAT}_{33}$ and $\mathrm{FAT}_{16}$ after 23 days. Increasing effects were observed after the second application on day 10 of FAT $_{16}$ (Fig. 3d). No recovery was observed in $\mathrm{CAT}_{33}$, while partial recovery was observed for $\mathrm{SAT}_{33}$ and $\mathrm{FAT}_{16}$. At the end of the experiment, densities of $D$. gr. longispina were very similar in the $\mathrm{SAT}_{33}$ and $\mathrm{FAT}_{16}$ treatments (characterised by the same 42-d TWA concentration). For CAT 10 , significant effects could be demonstrated only on day 2 (Fig. 3d).

\section{Macroinvertebrates}

Over the experimental period, a total of 91 different macroinvertebrate taxa were found in the microcosms, which were dominated by Insecta (51 taxa), followed by Mollusca (19), Oligochaeta (7), Hirudinea (5), Turbellaria (5), Crustacea (3) and Hydracarina (1). Among the insects, Diptera and Ephemeroptera accounted for 36 and 14\% of total abundance of macroinvertebrates, respectively, of which Chaoborus obscuripes and Cloeon dipterum were the most abundant taxa. Macrocrustaceans comprised $22 \%$ of the total macoinvertebrate abundance and were 
represented by Gammarus pulex, Asellus aquaticus and Proasellus meridianus/coxalis. Among the non-arthropods, the most abundant taxonomic groups were the Hirudinea and Gastropoda, which accounted for approximately 9 and $11 \%$ of total invertebrate abundance, respectively. Erpobdella sp. was the most abundant taxon in Hirudinea while Valvata sp. was the most abundant taxon in Gastropoda.

At the community level, the PRC analysis of the macroinvertebrate dataset indicated no effects, which was confirmed by the results of the Monte Carlo permutation tests $(p>0.05$; results not shown). At the species level, statistically significant declines in abundance relative to controls were observed only for Chaoborus obscuripes (Fig. 4), in the $\mathrm{FAT}_{16}$ treatment in particular. For this treatment, recovery was observed at the end of the experiment (Fig. 4). A similar decline was not observed in the $\mathrm{CAT}_{33}$ treatment, characterised by both a higher peak concentration and a higher 42-d TWA concentration than the $\mathrm{FAT}_{16}$ treatment.

Phytoplankton and periphyton

Over the experimental period, a total of 201 different phytoplankton taxa were identified in the microcosms. In terms of numbers of taxa as well as total abundance, the most important taxonomic groups were Chlorophyta (green algae), Charophyta (green algae), Cyanobacteria (bluegreen algae) and Bacillariophyta (diatoms). Among the Chlorophyta, the most abundant taxa were Sphaerocystis (Tetrasporales; Chlorophyceae) and Chlorophyta 2-5 $\mu \mathrm{m}$, which accounted for $16 \%$ and $3 \%$ of the total phytoplankton abundance, respectively. For Cyanobacteria, the most abundant taxa were Chroococcales $2-5 \mu \mathrm{m}$ colony

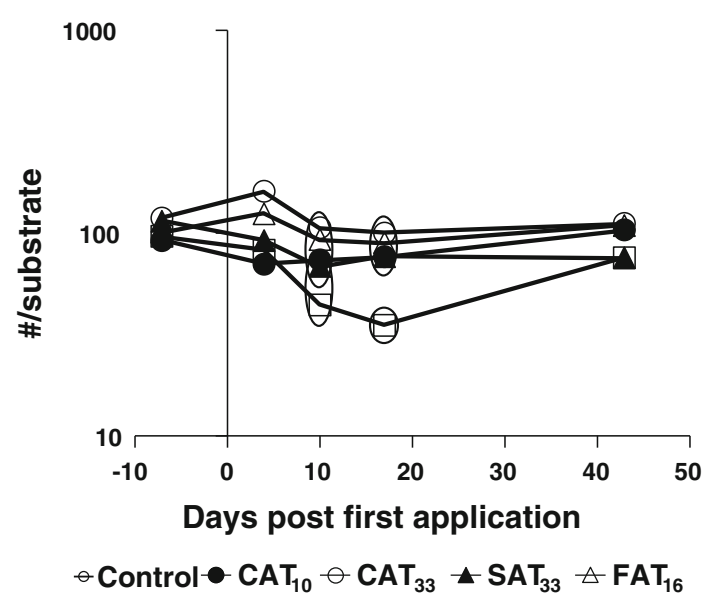

Fig. 4 Population dynamics of Chaoborus obscuripes in numbers per substrate (geometric mean). Significant differences are indicated by the circles. Treatments present in the same circle did not differ significantly from each other, while those not sharing the same circle did differ significantly (Duncan test, $p<0.05$ )
(53\%), Chroococcales 1-2 $\mu \mathrm{m}$ colony (7\%), followed by Pseudanabaena (4\%) and Pannus planus (3\%).

The multivariate analysis showed no significant community-level responses to the treatment (Monte Carlo permutation test, $p>0.05$ ). In addition, consistent and statistically significant effects at the population level were only detected for Tetraedron minimum, which showed a significant reduction in $\mathrm{CAT}_{10}, \mathrm{SAT}_{33}$ and $\mathrm{FAT}_{16}$ on the last two sampling dates relative to controls.

Chlorophyll- $a$ content of phytoplankton ranged between 0.00 and $36.76 \mu \mathrm{g} / \mathrm{L}$. For periphyton values ranged between 10.09 and $58.97 \mu \mathrm{g} / \mathrm{cm}^{2}$. No statistical differences between the various treatments and the controls were detected (Duncan test, $p<0.05$ ).

\section{Macrophytes}

Over the experimental period, a total of 14 different species of macrophyte were monitored in the microcosms. Rooted submerged macrophyte formed the majority of taxa, comprising of 3 Potamogeton species followed by 2 Elodea species. The multivariate statistical analysis indicated that the macrophyte community was not significantly affected by azoxystrobin (Monte Carlo permutation test, $p>0.05$ ). Univariate analysis of populations indicated statistically significant deviations (Duncan test, $p<0.05$ ) for Spirodela polyrhiza, by the end of experiment.

For the bioassays, 14 days after the start of the azoxystrobin exposures, the number of shoots of $M$. spicatum was significantly higher in $\mathrm{CAT}_{10}$ and $\mathrm{CAT}_{33}$ compared to the controls (Fig. 5a). The mean length of the shoots was significantly reduced in $\mathrm{CAT}_{33}$ at the same sampling time (day 14, Fig. 5b). Significant effects on dry weight of roots were also detected 14 days after the azoxystrobin application in the $\mathrm{SAT}_{33}$ and $\mathrm{CAT}_{33}$ treatments (Fig. 5c). No consistent significant effects were detected in any treatment on other endpoints (i.e., dry weight of shoots and total length of shoot), nor on the final biomass of macrophyte species (mean dry weight for all cosms $=128 \pm 27 \mathrm{~g} \mathrm{dw} / \mathrm{m}^{2}$, mean $\pm \mathrm{SD})$.

\section{Decomposition}

No significant effects of the azoxystrobin treatments (Duncan test, $p<0.05$ ) were detected in the breakdown of particulate organic matter (POM). The remaining dry weight of leaves in litterbag over the whole experimental period including all microcosms was $80 \pm 7 \%$ (mean \pm SD).

Water quality analysis

The water quality variables DO, EC, T and alkalinity did not reveal consistent treatment-related responses and mean 
Fig. 5 Results of the bioassays performed with Myriophyllum spicatum. Number of shoots (a), mean length of shoots (b) and weight of roots (c). Significant differences are indicated by the circles (Duncan test, $p<0.05$ ). Treatments present in the same circle did not differ significantly from each other, while those not sharing the same circle did differ significantly
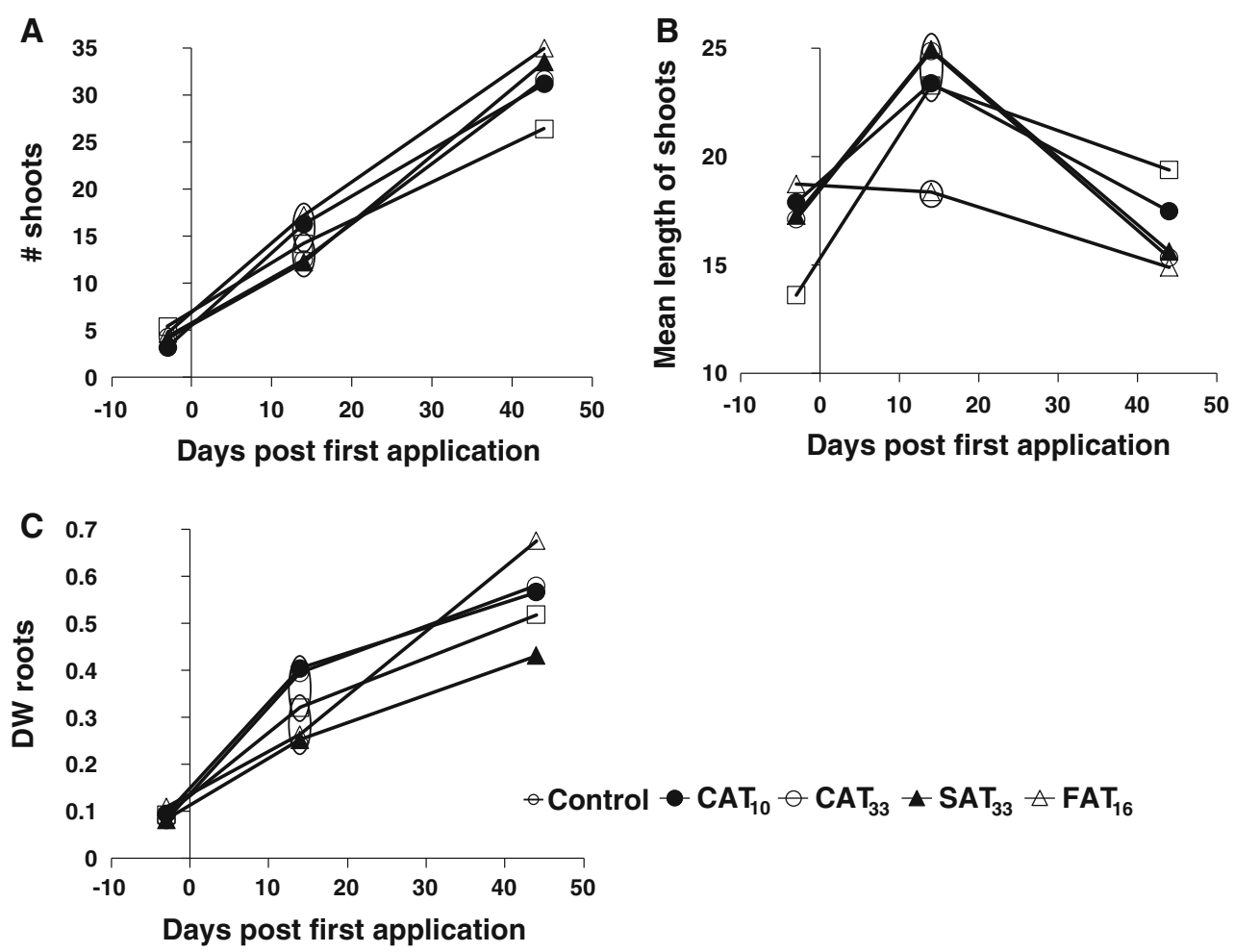

values in all microcosms during the entire experimental period were $10.6 \pm 1.0 \mathrm{mg} / \mathrm{L} ; 115 \pm 14 \mu \mathrm{S} / \mathrm{cm}^{2} ; 19 \pm$ $0.8^{\circ} \mathrm{C}$, and $0.84 \pm 0.05 \mathrm{meq} / \mathrm{L}$, respectively. An increase in $\mathrm{pH}$ was observed for most treatment levels, but kept within one $\mathrm{pH}$ unit (Fig. 6). At day 16, pH values were statistically significantly elevated in $\mathrm{CAT}_{10}, \mathrm{SAT}_{33}$ and $\mathrm{FAT}_{16}$ while on day 23, in $\mathrm{CAT}_{10}, \mathrm{CAT}_{33}$ and $\mathrm{SAT}_{33}$. Notably, deviations of these treatments were statistically significant relative to control rather than from each other

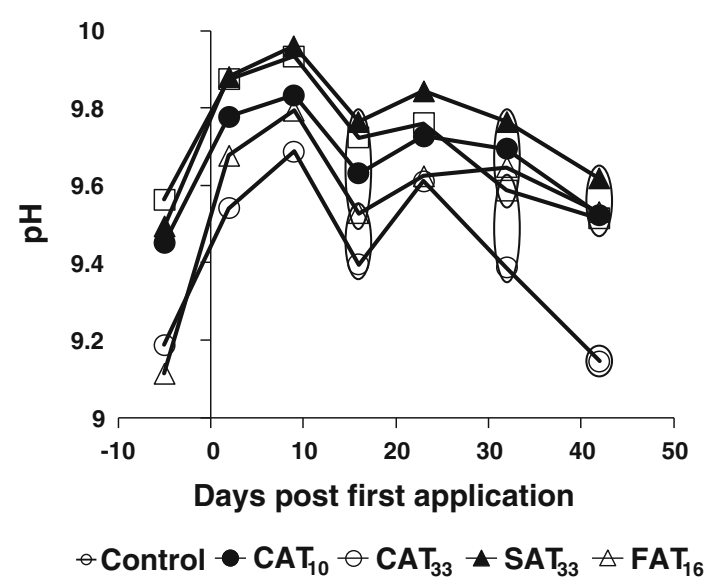

Fig. 6 Dynamics of $\mathrm{pH}$ in the different treatments. Significant differences are indicated by the circles. Treatments present in the same circle did not differ significantly from each other, while those not sharing the same circle did differ significantly
(Fig. 6). All treatment regime $\mathrm{pH}$ values were significantly different to the control at the end of experiment (Fig. 6).

The concentrations of the ammonia, nitrate and nitrite, and ortho-phosphate were below the LODs of $0.04,0.03$ and $0.02 \mathrm{mg} / \mathrm{L}$, respectively. No significant effects were found on the total phosphate and total soluble nitrogen levels (concentrations between 0.60 and $1.01 \mathrm{mg} / \mathrm{L} ;<\mathrm{LOD}$ and $0.14 \mathrm{mg} / \mathrm{L}$, respectively).

\section{Discussion}

Comparison across time-variable exposure regimes (similar peak vs. similar 42-d TWA)

To determine which effects can be assessed by the peak and TWA $_{42 \mathrm{~d}}$ exposure concentrations, treatment-related impacts of $\mathrm{SAT}_{33}$ and $\mathrm{CAT}_{33}$ were compared because they had a similar initial peak concentration (different TWA), and those of $\mathrm{SAT}_{33}$ and $\mathrm{FAT}_{16}$ are compared because they had similar TWA concentrations (but different peak concentrations). At the community level, the PRC diagram resulting from analysis of zooplankton data-set (Fig. 2) elucidates small and similar sized magnitude of effects among different timevariable exposure profiles $\left(\mathrm{SAT}_{33}, \mathrm{FAT}_{16}\right.$ and $\mathrm{CAT}_{33}$ ) shortly after the start of the experiment (day 2), while the effects in the $\mathrm{SAT}_{33}$ and $\mathrm{CAT}_{33}$ increased in magnitude on day 9. The time-variable exposure regimes that have similar initial peak concentrations $\left(\mathrm{SAT}_{33}\right.$ and $\mathrm{CAT}_{33}$ ) resulted in 
comparable effects on the zooplankton community until day 9, but not afterwards. This indicates that the peak concentration is a good predictor of short-term effects only. The magnitude of effect in $\mathrm{SAT}_{33}$ was pronounced relative to FAT $_{16}$ until day 9, after which the magnitude of effects increased in $\mathrm{FAT}_{16}$ to become similar to that in $\mathrm{SAT}_{33}$ (from day 16 onwards). Since both these pulsed treatment regimes are characterised by the same 42-d TWA concentration, it can be concluded that the similar TWA concentrations cause a comparable effects on the zooplankton community in the long-term. These results support the ELINK recommendation that for long term effects the TWA concentration can be more relevant than the peak concentration (Brock et al. 2010). During the last few years, several workshops and projects have proposed using the TWA concentration approach, instead of the nominal peak concentration for assessing effects of repeated exposures (ECOFRAM 1999; Boxall et al. 2001; Reinert et al. 2002; Boesten et al. 2007; Brock et al. 2010).

The finding that TWA is a better predictor of effects also holds true at the taxon level. Several taxa such as nauplii, adult Cyclopoida and Daphnia gr. longispina clearly show similar survival responses to the different time-variable exposure regimes (Fig. 3a, c and d), i.e., similar effect magnitude for the $\mathrm{SAT}_{33}$ and $\mathrm{CAT}_{33}$ treatments (similar peak concentration) during the first 1.5 week after the first application and similar effect magnitudes for the $\mathrm{FAT}_{16}$ and $\mathrm{CAT}_{33}$ treatments (similar TWA concentrations) at the end of the experiment.

For the risk assessment of azoxystrobin, it is not so surprising that the short-term effects observed due to different peak concentrations in the microcosm experiment can be related to measured or predicted peak concentrations. The results suggest that long-term effects can be assessed by comparing TWA rather than peak concentrations, even if the dynamics of the pulses are different. Zafar et al. (2011) also found similar relationships between longterm effects and TWA concentrations for most invertebrate species exposed to chlorpyrifos in microcosm under different exposure profiles with the same TWA concentration. They also concluded that for the applied combination of concentration dynamics, the TWA concentration was a more adequate predictor for long-term risks of chlorpyrifos for most species than the peak concentration. After performing long-term toxicity tests with Gammarus. pulex, Ashauer et al. (2007) also concluded that the TWA concentration approach can be used to predict effects of repeated pulses of chlorpyrifos and pentachlorophenol.

Fate of azoxystrobin in the water column

The dissipation rate of azoxystrobin in the $\mathrm{SAT}_{33}$ treatment of the present study (18 days) is consistent with those of previous studies, which reported half-life values in the range of 15-25 days (Gustafsson et al. 2010) and 13 days (Jones and Lake 2000). The dissipation is probably a result of photolysis, since the US-EPA (1997) reported a half-life of 11-17 days in aquatic environments for photolysis only. Also, the potential for accumulation in sediments is low $\left(\log \mathrm{K}_{\mathrm{ow}}=2.50\right)$ and azoxystrobin is a non-volatile compound (Henry's Law constant $=7.3 \times 10^{-9} \mathrm{~Pa} \times \mathrm{m}^{3} / \mathrm{mol}$ (Tomlin 2011). The higher peak concentration in all treatments measured $4 \mathrm{~h}$ after application compared to the nominal concentrations may be attributed to non-homogeneity of azoxystrobin in the water layer as a result of dominant aquatic vegetation and therefore incomplete mixing of dosed solutions within the microcosm.

\section{Biological effects of azoxystrobin}

The PRC diagram of the zooplankton community indicated pronounced treatment dependent negative impacts of azoxystrobin (Fig. 3). The largest adverse effects were reported for nauplii, adult Calanoida and Cladocera, followed by adult Cyclopodia. For most taxa these changes persisted until the end of study (Figs. 2, 3). These results are consistent with the other model ecosystem studies available and suggest that some copepods are sensitive to azoxystrobin (Cole et al. 2000; Gustafsson et al. 2010). Furthermore, in the present study, naupliar stages of copepods were found to be more sensitive to azoxystrobin than adult cyclopoids, which is in agreement with observations reported by Gustafsson et al. (2010).

The decrease in numbers of calanoid copepods in all treatments just after the start of the treatment (Fig. 3b) is similar to other observations by Lauridsen et al. (2003). They performed a series of acute and sub-chronic toxicity tests with azoxystrobin on several different freshwater zooplankton and macroinvertebrate species and found that the calanoid copepod Eudiaptomus graciloides was the most sensitive among the tested taxa. In the present study, cyclopoid copepods were vulnerable to all treatments except for $\mathrm{CAT}_{10}$ (Fig. 3c). This is not in line with the observations by Cole et al. (2000) who reported effects directly after a single application of $10 \mu \mathrm{g} / \mathrm{L}$. This may be a result of differences between the species composition of the Copepoda community. The effects in this study agree with the laboratory tests performed by Lauridsen et al. (2003) with the cyclopoid copepod Cyclops vicinus, in which all individuals died within $48 \mathrm{~h}$ when exposed to $20 \mu \mathrm{g} / \mathrm{L}$ or higher, and a NOEC for reproduction of $10 \mu \mathrm{g} /$ $\mathrm{L}$ was reported. Effects on Copepoda populations have also been reported longer than 3 weeks period on Copepoda populations after a single application of $3,7.5,15$, and $60 \mu \mathrm{g} / \mathrm{L}$ (Gustafsson et al. 2010). 
The PRC diagram and univariate analysis showed a negative impact of azoxystrobin on one taxon of Cladocera, i.e., D. gr. longispina, while other taxa like Simocephalus vetulus, Alona sp. and Alonella sp. experienced no effects (Fig. 2). This is in accordance with the study of Cole et al. (2000), who reported significant reductions of Daphnia spp. after single applications of 10 and $30 \mu \mathrm{g} / \mathrm{L}$ and also reported significant increase in numbers for Chydorus sp. It was shown by Lauridsen et al. (2003) that some cladocerans (D. magna, Chydorus sphaericus and Ceriodaphnia sp.) were relatively tolerant to azoxystrobin while others (D. galeata) were much more sensitive. Their physiological experiments (e.g., pectoral limb, hind claw, mandible and heart activity) clearly demonstrated that azoxystrobin may affect zooplankton in different ways.

Treatment-related impacts on the macroinvertebrate community were not found. On the basis of information already known for azoxystrobin, it is reasonable to assume that invertebrates, in particular macroinvertebrate crustaceans and insects, are not highly sensitive to azoxystrobin, which is supported by the results of Cole et al. (2000). C. obscuripes was the only macroinvertebrate species which responded significantly to the $\mathrm{FAT}_{16}$ treatment (Fig. 4). The observed effect in the FAT $_{16}$ treatment is probably not a direct effect since it did not show a clear treatment-response pattern. The effects observed are consistent with the microcosm study conducted by Cole et al. (2000) who reported no significant effects on any macroinvertebrates after single applications of 10 and $30 \mu \mathrm{g} / \mathrm{L}$ and observed some effects on Gammaridae and Mollusca at $100 \mu \mathrm{g} / \mathrm{L}$. Lauridsen et al. (2003) reported no effects on Chaoborus flavicans up to azoxystrobin concentrations of $6,000 \mu \mathrm{g} / \mathrm{L}$ and no significant effects were detected on Chaoboridae after a single application of 1,000 $\mu \mathrm{g}$ azoxystrobin/L in the microcosm study performed by Cole et al. (2000). The observed effects might be a result of temporally decreased food availability in the form of $D$. gr. longispina (Fig. 3), while its fast recovery can be explained by the multivoltine life cycle of $C$. obscuripes in The Netherlands (Van Wijngaarden et al. 2006). Further studies performed by Lauridsen et al. (2003) on three other macroinvertebrate species, i.e., Chironomus plumosus, Cloeon dipterum and Hydropsyche angustipennis, also revealed no effects at treatment levels of 525, 1,500 and 3,000 $\mu \mathrm{g} / \mathrm{L}$, respectively. Apparently, the sensitivity-tolerance spectrum for this chemical is very wide for different arthropod species.

Compared to the controls, the composition of the phytoplankton community was not altered by the azoxystrobin treatments, which is in agreement with Cole et al. (2000). On day 22, the abundance of Tetraedron minimum had increased in the control and the $\mathrm{CAT}_{33}$ treatments, and abundance was still elevated at day 42 in these treatments. It is difficult to explain the significantly lower numbers in the other treatments relative to the control, as a result of direct or indirect effects of azoxystrobin as effects were not observed in the treatment with the highest peak and TWA concentration (i.e., $\mathrm{CAT}_{33}$ ). A significant increase of the macrophyte Spirodela polyrhiza coverage occurred in the $\mathrm{CAT}_{33}, \mathrm{SAT}_{33}$ and $\mathrm{FAT}_{16}$ treatments in the range of $\%$ cover of $<1 \%$ and is, therefore, not considered important from ecological point of view. The absence of systematic effects on macrophytes in this study (Fig. 5) is in agreement with the high growth $\mathrm{EC}_{50}(3,200 \mu \mathrm{g} / \mathrm{L})$ determined for the macrophyte Lemna gibba in a laboratory toxicity study (Tomlin 2011). As a result of this lack of effects on macrophytes, the water physico-chemical parameters were not greatly influenced by azoxystrobin treatments. Of all the physico-chemical variables, $\mathrm{pH}$ values in treated systems were slightly (and sometimes statistically significantly) higher than in the controls (Fig. 6). This could be a result of increased algal biomass due to a reduced grazing pressure by $D$. gr. longispina, but this was, however, not reflected in significant increases in phytoplankton and periphytonic chlorophyll- $a$. The observations in the present study are in accordance with Gustafsson et al. (2010) who found marginally significant differences on one sampling day for chlorophyll- $a$ concentration in water at azoxystrobin concentrations of 5 and $20 \mu \mathrm{g} / \mathrm{L}$, although it should be noted that this experiment was performed in brackish water. The increase in $\mathrm{pH}$ values remained within one $\mathrm{pH}$ unit and are, therefore, considered to be of low ecological relevance. In line with this, Cole et al. (2000) also found significant differences in $\mathrm{pH}$ relative to the control, following a single application of $10 \mu \mathrm{g} / \mathrm{L}$, but on individual sampling dates only. No effects were observed on decomposition in all treatment regimes which is consistent with Gustafsson et al. (2010) who reported that degradation of organic material in their microcosms was not affected by azoxystrobin treatment during the course of experiment.

According to the EU Guidance Document on Aquatic Ecotoxicology, the no observed ecologically adverse effect concentrations (NOEAEC) is the concentration at or below which no long-lasting adverse effects were observed in the microcosm study (European Commission 2002). If we translate short-lasting effects to effect class 1 or 2 (based on effect classes; Brock et al. 2006), the NOEAEC of this study can be set at the $\mathrm{CAT}_{10}$ treatment, which is in accordance with the NOEAEC of a previous microcosm study (Cole et al. 2000) which was set at a single application of $10 \mu \mathrm{g} / \mathrm{L}$.

\section{Conclusions}

The present study shows that under the tested exposure regimes and for the endpoints studied, the TWA is a more 
adequate predictor for long-term effects of azoxystrobin on the zooplankton community and species than the peak concentration. These results support the recommendation of the ELINK workshop that for long-term effects of pesticides, a risk assessment based on TWA concentrations may be more relevant than one based on peak concentrations. It should be noted however that this conclusion only applies to the zooplankton community and species, since effects on other endpoints were limited.

Acknowledgments The present study received financial support from the Dutch Ministry of Economic Affairs, Agriculture and Innovation while the author Mazhar Iqbal Zafar is sponsored by a $\mathrm{PhD}$ grant with the collaboration of the NUFFIC - Netherlands organisation for international cooperation in higher education and HEC - Higher Education Commission of Pakistan scholarship programme. We like to thank Theo Brock, Gertie Arts, Ivo Roessink, Marie-Claire Boerwinkel, Harry Boonstra, Caroline van RhenenKersten, John Deneer, Nika Galić, René Aalderink, Hans Zweers, Steven Crum, and Laura Buijse for assistance during the study.

Open Access This article is distributed under the terms of the Creative Commons Attribution License which permits any use, distribution, and reproduction in any medium, provided the original author(s) and the source are credited.

\section{References}

Ashauer R, Boxall ABA, Brown CD (2007) Modeling combined effects of pulsed exposure to carbaryl and chlorpyrifos on Gammarus Pulex. Environ Sci Technol 41:5535-5541

Bartlett DW, Clough JM, Goodwin JR, Hall AA, Hamer M, ParrDobrzanski B (2002) The strobilurin fungicides. Pest Manag Sci 58:647-662

Boesten JJTI, Köpp H, Adriaanse PI, Brock TCM, Forbes VE (2007) Conceptual model for improving the link between exposure and effects in the aquatic risk assessment of pesticides. Ecotoxicol Environ Saf 66:291-308

Boxall A, Brown C, Barrett K (2001) Higher tier laboratory aquatic toxicity testing. Cranfield centre for EcoChemistry research report No. JF 4317E for DETR, Canfield

Brock TCM, Huijbregts CAM, Van de Steeg-Huberts MJ, Vlassak MA (1982) In situ studies on the breakdown of Nymphoides peltata (Gmel.) O. Kuntze (Menyanthaceae); Some methodological aspects of the litter bag technique. Hydrobiol Bull 16:35-49

Brock TCM, Crum SJH, Wijngaarden R, Budde BJ, Tijink J, Zuppelli A, Leeuwangh P (1992) Fate and effects of the insecticide Dursban ${ }^{\circledR} 4 \mathrm{E}$ in indoor Elodea-dominated and macrophyte-free freshwater model ecosystems: I. Fate and primary effects of the active ingredient chlorpyrifos. Arch Environ Contam Toxicol 23:69-84

Brock TCM, Arts GHP, Maltby L, Van den Brink PJ (2006) Aquatic risks of pesticides, ecological protection goals and common aims in EU Legislation. Integr Environ Assess Manag 2:e20-e46

Brock TCM, Alix A, Brown CD, Capri E, Gottesbüren BFF, Heimbach F, Lythgo CM, Schulz R, Streloke M (2010) Linking aquatic exposure to effects: risk assessment of pesticides. CRC, Boca Raton

Cole JFH, Everett CJ, Gentle W, Ashwell JA, Goggin U (2000) Azoxystrobin: an outdoor pond microcosm study. ZENECA
Agrochemicals. Jealott's Hill International Research Centre. Report number RJ2857B, Bracknell (summarised and cited in EFSA 2009)

ECOFRAM (1999) Ecological committee on fifra risk assessment methods (ECOFRAM) ECOFRAM draft aquatic report. US Environmental Protection Agency, Pennsylvania

EFSA (2009) Council directive 91/414/EEC. Azoxystrobin. Report and proposed decision of the United Kingdom made to the European Commission under commission regulation 737/2007. Accessed via http://dar.efsa.europa.eu/dar-web/provision

European Commission (2002) Guidance document on aquatic toxicology in the context of the Directive 91/414/EEC. Working Document of the European Commission Health \& Consumer Protection Directorate-General, Brussels

European Commission (2009) Regulation (EC) No 1107/2009 of the European Parliament and of the Council of 21 October 2009 concerning the placing of plant protection products on the market and repealing Council Directives 79/117/EEC and 91/414/EEC. Off J Eur Comm L 309:1-50

Gustafsson K, Blidberg E, Elfgren I, Hellström A, Kylin H, Gorokhova E (2010) Direct and indirect effects of the fungicide azoxystrobin in outdoor brackish water microcosms. Ecotoxicology 19:431-444

Jones RN, Lake A (2000) Azoxystrobin: distribution in an outdoor pond. ZENECA Agrochemicals Report no. RJ 3062B, Bracknell (summarised and cited in EFSA 2009)

Lauridsen TL, Friberg-Jensen U, Cristoffersen K (2003) Effekter af cypermethrin, azoxystrobin og bentazon på limniske invertebrater. Rep. 76, Miljøstyrelsen, Miljøministeriet (in Danish), Copenhagen

Maltby L, Brock TCM, Van den Brink PJ (2009) Fungicide risk assessment for aquatic ecosystems: importance of interspecific variation, toxic mode of action, and exposure regime. Environ Sci Technol 43:7556-7563

Reinert KH, Giddings JM, Judd L (2002) Effects analysis of timevarying or repeated exposures in aquatic ecological risk assessment of agrochemicals. Environ Toxicol Chem 21:1977-1992

Slijkerman DME, Baird DJ, Conrad A, Jak RG, van Straalen NM (2004) Assessing structural and functional plankton responses to carbendazim toxicity. Environ Toxicol Chem 23:455-462

Ter Braak CJF, Smilauer P (2002) CANOCO reference manual and CanoDraw for windows user's guide: software for canonical community ordination (version 4.5). Microcomputer Power, Ithaca (www.canoco.com)

Tomlin CDS (2011) The pesticide manual world compendium, 15th edn. British Crop Protection Council, Surrey

US-EPA (1997) Pesticide tolerance petition filing for azoxystrobin. Federal Register Document 97-5683. Mar 11, 1997

Van den Brink PJ (2008) Ecological risk assessment: from bookkeeping to chemical stress ecology. Environ Sci Technol 42: 8999-9004

Van den Brink PJ, Ter Braak CJF (1999) Principal response curves: analysis of time-dependent multivariate responses of biological community to stress. Environ Toxicol Chem 18:138-148

Van den Brink PJ, Hattink J, Bransen F, Van Donk E, Brock TCM (2000) Impact of the fungicide carbendazim in freshwater microcosms. II. Zooplankton, primary producers and final conclusions. Aquat Toxicol 48:251-264

Van Wijngaarden RPA, Brock TCM, Van den Brink PJ, Gylstra R, Maund S (2006) Ecological effects of spring and late summer applications of Lambda-Cyhalothrin on freshwater microcosms. Arch Environ Contam Toxicol 50:220-239

Warming T, Mulderij G, Christoffersen K (2009) Clonal variation in physiological responses of Daphnia magna to the strobilurin fungicide azoxystrobin. Environ Toxicol Chem 28:374-380 
Webb DJ, Burnison BK, Trimbee AM, Prepas EE (1992) Comparison of chlorophyll a extractions with ethanol and dimethyl sulfoxide/ acetone, and a concern about spectrophotometric phaeopigment correction. Can J Fish Aquat Sci 49:2331-2336
Zafar MI, Van Wijngaarden RPA, Roessink I, Van den Brink PJ (2011) Effects of time-variable exposure regimes of the insecticide chlorpyrifos on freshwater invertebrate communities in microcosms. Environ Toxicol Chem 30:1383-1394 